\title{
The teaching of computer ethics on computer science and related degree programmes. a European survey
}

\author{
loannis Stavrakakis ${ }^{1}$ D Damian Gordon ${ }^{1} \cdot$ Brendan Tierney $^{1} \cdot$ \\ Anna Becevel ${ }^{1} \cdot$ Emma Murphy $^{1} \cdot$ Gordana Dodig-Crnkovic $^{2} \cdot$ Radu Dobrin $^{3}$. \\ Viola Schiaffonati ${ }^{4}$. Cristina Pereira ${ }^{5}$. Svetlana Tikhonenko ${ }^{5}$. J. Paul Gibson ${ }^{6}$. \\ Stephane Maag $^{6} \cdot$ Francesco Agresta $^{7}$. Andrea Curley ${ }^{1} \cdot$ Michael Collins $^{1}$. \\ Dympna O'Sullivan ${ }^{1}$
}

Accepted: 24 August 2021 / Published online: 6 October 2021

(C) The Author(s) 2021

\begin{abstract}
Within the Computer Science community, many ethical issues have emerged as significant and critical concerns. Computer ethics is an academic field in its own right and there are unique ethical issues associated with information technology. It encompasses a range of issues and concerns including privacy and agency around personal information, Artificial Intelligence and pervasive technology, the Internet of Things and surveillance applications. As computing technology impacts society at an ever growing pace, there are growing calls for more computer ethics content to be included in Computer Science curricula. In this paper we present the results of a survey that polled faculty from Computer Science and related disciplines about teaching practices for computer ethics at their institutions. The survey was completed by respondents from 61 universities across 23 European countries. Participants were surveyed on whether or not computer ethics is taught to Computer Science students at each institution, the reasons why computer ethics is or is not taught, how computer ethics is taught, the background of staff who teach computer ethics and the scope of computer ethics curricula. This paper presents and discusses the results of the survey.
\end{abstract}

Keywords Ethics · Computer Ethics · Teaching Computer Ethics · Computer Science Education

Ioannis Stavrakakis

ioannis.stavrakakis@tudublin.ie

Extended author information available on the last page of the article 


\section{Introduction}

Computers and technological applications are now central to many aspects of life and society, from industry and commerce, government, research, education, medicine, communication, and entertainment systems. Computer Scientists and professionals from related disciplines who design and develop computer applications have a significant responsibility as the systems they develop can have wide ranging impacts on society where those impacts can be beneficial but may also at times be negative. The last decade has seen rapid technological growth and innovation, with the realities of Artificial Intelligence technology and related applications coming to fruition. Increasingly there is a sense that we are developing technology faster than we are assessing its moral and ethical implications.

Computer ethics, defined as "the analysis of the nature and social impact of computer technology and the corresponding formulation and justification of policies for the ethical use of such technology" (Moor, 1985, p.266), has a long history, dating back to the works of Wiener on Cybernetics almost 70 years ago. Over the years many variations of the term computer ethics have entered the literature including computing ethics, information ethics, informatics ethics, ICT Ethics, IT ethics and ethics of information systems (Stahl et al., 2016). These terms reflect the widespread and increasingly pervasive use and impacts of computing technology in all areas of society such as education, transportation, governance and so on (Dodig-Crnkovic, 2003).

As such, in this paper we use the term "computer ethics" as a broad term to encompass a wide range of topics related to computer technology and ethics, including computing ethics, information ethics, informatics ethics, ICT Ethics, IT ethics and ethics of information systems. Despite the long history of computer ethics and many academic discussions on the topic, professional ethics for designers and developers of computer technology are less well developed than for those in other fields such as medical, legal and business and engineering ethics. Computer Science is still a relatively young and still evolving discipline. Furthermore, the ethical questions faced by Computer Scientists are often more nuanced than those faced by other professions. For example, in Engineering education, the classic ethical case studies depict losses of life or injury as a result of ethical lapses in these fields. e.g. the Ford Pinto fires or the collapse of the Hyatt walkway in Kansas City. While some Computer Scientists build safety critical systems, many others develop systems that are non-critical from a safety perspective, but at the same time have wide societal impacts. For example, commercial and government systems such social media platforms, predictive analytics for consumer behaviours or surveillance technologies. Some of the impacts of such systems are intended, for example, to encourage online consumers to purchase goods or services or to automate human-centric tasks. However, unintended consequences of new technologies are becoming increasingly obvious - code developed for one purpose in a specific system can be reused in another system where it could different or even ethical consequences. These consequences have increasingly come into public view, for example, how data harvested illegally from social media platforms was used to influence voters in elections in the US and 
the UK or how automated decision making software displayed gender and racial biases when shortlisting applicants for jobs.

As such it is important that graduates of Computer Science and related programmes are equipped to consider the ethical dimensions of the technology they will design and develop in their professional lives. It is becoming more commonplace for institutions to prioritize integrating computer ethics into their Computer Science curricula so students don't just learn about how to build software, but also they learn how to analyse the potential negative consequences of any software they design and build. Finally, with more and more countries introducing computing into school curricula (Passey, 2017; Sentance \& Csizmadia, 2017) with the aim of creating a whole new learning culture (Brodnik \& Lewin, 2017), Computer Science will come to play an even more important role in all levels of education, thus making computer ethics an imperative field of knowledge for all educators.

In this paper we outline the results of a large scale survey of European academics about existing competencies in the teaching of computer ethics in Computer Science and related disciplines (Ethics4EU, 2021). The survey was completed by respondents from 61 universities across 23 European countries. Respondents were surveyed on whether or not computer ethics is taught to Computer Science students at each institution, the reasons why computer ethics is or is not taught, how computer ethics is taught (for example, as a standalone course or embedded within other modules), the background of staff who teach computer ethics and the scope of computer ethics curricula. Data was also gathered on teaching and learning methods used (theory, case studies, practical work) and how computer ethics is assessed. The survey was conducted as part of an Erasmus + project, Ethics4EU that is focused on developing new computer ethics curricula and learning materials for faculty teaching Computer Science. The aim of the survey was to provide a comprehensive insight into teaching practices for computer ethics in Computer Science and related disciplines which will be used to guide the development of new teaching and learning resources.

The rest of this paper is organized as follows. In the next section, we present a literature review about the teaching of computer ethics in Computer Science. In Section 3 we present our survey methodology. In Section 4 we present and discuss the finding from our survey. We conclude with a discussion in Section 5.

\section{Literature review}

Computer ethics have been the subject of academic research for many years. In The Human Use of Human Beings (Wiener, 1950), Wiener wrote about how computers have the potential to drastically alter the communication mechanisms and therefore transform the fabric of societies namely social policies, law, the economy and personal relationships. The issues he identified in included topics that are still important today: computers and security, computers and unemployment, responsibilities of computer professionals, computers for persons with disabilities, information networks and globalization, virtual communities, teleworking, merging of human bodies with machines, robot ethics, artificial intelligence, computers and religion, and a number of other subjects (Bynum, 2000). 
In the 1970s Walter Maner coined the term 'computer ethics' recognising an important new area of applied ethics and was one of the first academics to develop a computer ethics course for students (Bynum, 2008). In 1985 Debora Johnson published the seminal textbook Computer Ethics (D. Johnson, 1985) where she stated that computers "pose new versions of standard moral problems and moral dilemmas, exacerbating the old problems, and forcing us to apply ordinary moral norms in uncharted realms." "Computer Ethics" quickly became the primary text used to teach computer at universities. The textbook also set the research agenda on topics such as ownership of software and intellectual property, computing and privacy, responsibilities of computer professionals, and fair distribution of technology and human power. In later editions in 1994, 2001 and 2009, Johnson added new ethical topics such as hacking, inclusive technologies for persons with disabilities, and Internet ethics.

A different emphasis for computer ethics was advocated by Donald Gotterbarn (Gotterbarn, 1991), who believed that computer ethics should be seen as a professional ethics devoted to the development and advancement of standards of good practice and codes of conduct for computing professionals. In the 1990s Gotterbarn's professional ethics approach purported that Computer Science students should be taught their professional responsibilities, standards and reasoning skills to deal with emerging and future ethical issues relevant to their profession as well as specific values and avoid malpractice (Iqbal \& Beigh, 2017). Gotterbarn's position was complemented by the publication of the ACM's Code of Ethics and Professional Conduct in 1991 which included recommendations to teach social and ethical issues as part of undergraduate Computer Science curricula (Bynum, 2008, 1992; Fuller et al., 2010; Tucker, 1991).

The approach of teaching computer ethics as a standalone professional ethics subject or for it to be delivered as an external course, often outsourced to a different department like that of Philosophy or Social Sciences, sometimes devoid of technical context has pervaded for some time (Skirpan et al., 2018). For example, a survey from 2019 by Saltz et al. (2019) examined the syllabi of machine learning courses from a large number of third level institutions in the US and found that for a majority of programmes, students are not taught any ethics content and for those that are, it is usually a stand-alone elective course. It is only recently that scholars have argued that since every computer-related subject carries social or ethical implications, then these ethical topics should be widely integrated and infused in Computer Science curricula (Harris et al., 2019; Weikle, 2018). For example, Grosz et al. (2019) argue that modern technology cannot be considered "value-neutral" (p. 54); it can have unplanned consequences and that Computer Science students should be trained to identify the potential harmful effects of the technologies they help develop. An important concept that students need to be able to think about is not only whether they can create something, but whether they should create it in the first place. The authors argue that teaching computer scientists to identify and address ethical problems starting from the design phase is as important as enabling them to develop algorithms and programs that work efficiently (p. 61). Therefore, they argue for the integration of computer ethics throughout the whole Computer Science curriculum. 
A recent paper (Fiesler et al., 2020) surveys Computer Science computer ethics classes in 94 universities located mainly in the US, showed that there is much variability in the content of computer ethics courses which they attribute to the lack of standards in this particular subject. This is not to say that there are no common patterns. Topics such as privacy, algorithms and inequality are considered critical. The study also highlighted a slight move from standalone computer ethics courses towards integrating computer ethics throughout technical courses. Scott and Barlowe (2016) describe an experimental Computer Science module that introduced first-year university students to basic programming with computer ethics and found that those students who had completed the course were more likely to do better during their first year of Computer Science. In related work, Ferrarello (2019) underline that social and ethical awareness when introduced into Design and Engineering education generally promotes the industry's capability to tackle ethical and social issues effectively. The study found that using methods such as workshops that adopted collaborative, engaged design approaches, facilitated discussion, debates and reflection helped the participants acknowledge responsibilities and the ownership of decision making in design and engineering.

At a postgraduate level, Dexter et al. (2013) investigated the requirement for computer ethics education on graduate level programmes in four diverse US academic institutions. They found that the majority of faculty and students were in favour of an elective computer ethics course and almost half were in favour of a compulsory computer ethics graduate course.

In terms of how computer ethics is taught, case-based analysis of ethical and societal issues of technology that have either appeared in the news or are part of hypothetical scenarios are a popular approach (Ghafarian, 2002; Kraft, 2011; Larson \& Miller, 2018; Quinn, 2006). This approach relies on precedent cases and paradigms to reach a conclusion about a test case. Larson and Miller (Larson \& Miller, 2018) argue that just reading about ethical issues is not enough, rather case-based analysis provides an environment where students can apply computer ethics and critical thinking in realistic scenarios. In a 2019 study Lester and Dalat-Ward (Lester \& Dalat-Ward, 2019) found that combining case-based learning and ethical decision making with deliberative dialogue and role playing was an efficient method to achieve the learning outcomes when compared to traditional lecture-based teaching. They also found that the students' self-confidence on the subject matter increased as well as their critical thinking skills and their openness towards differing viewpoints. However, one challenge the researchers discovered is the extensive preparation time required by faculty members before each class.

Deliberation appears to be a good tool for teaching ethics as shown in a 2020 study by Shen et al. (2020) where they used deliberation and Value Cards in a gamified teaching approach that combines technical training with topics such as Fairness, Accountability, Transparency and Ethics (FATE) for a Machine Learning class. Their aim was to help students understand the societal and ethical implications of machine learning-based algorithmic systems while taking into account diverse social values. They designed a set of Value Cards drawing from the research on value sensitive design and based on the concept of the Envisioning cards toolkit (Friedman \& Hendry, 2012). 
Others advocate interdisciplinary collaborations between different academic faculties as an effective way to deliver computer ethics. For example, Kesar (2016) created a computing curriculum that emphasizes interdisciplinary collaborations between academic departments, promotes industry interactions and supports students to develop critical ethical reasoning skills for real business settings. In a review, the majority of students identified the ethical and social properties of their projects rather than the technological aspects as the most complex issues. Another recent interdisciplinary approach was reported by Reich et al. (2020) who designed a multidisciplinary approach for teaching computer ethics at Stanford University. Their approach combines the expertise from the faculties of Philosophy, Political Science and Computer Science and includes panels of speakers and custom-built case studies. Wilk (2019) who proposes the creation of an entirely new Computer Science course titled "Computers, Ethics, Law, and Public Policy". The course would combine computer ethics with law and use examples and case studies to illustrate ethical and legal decision making. The author states the importance of teaching legal aspects to Computer Science students because as new technologies appear there will be new requirements to develop laws and computer ethics to address them.

Kortsarts and Fischbach (Kortsarts \& Fischbach, 2014) proposed an approach which combines together the ACM Code of Ethics and case-based design and analysis. More specifically, their approach to computer ethics constituted of three parts. The first part was about the students learning the ACM code of ethics and designing case studies. In the second part the students had to analyse said case studies. In the last part, the students had to review reading material from the ACM digital library and present their findings. The researchers found that over two thirds of the students found computer ethics to be important and would influence their decisionmaking process in the future and also said discovering the ACM Code of Ethics was worthwhile.

Drawing a parallel with the field of Engineering Ethics, which historically precedes Computer Ethics, Hess and Fore (2018) conducted a systematic literature review of US Engineering ethics interventions and found that the most common approaches were the use of case studies, exposure to professional codes and standards and discussion activities. Their study identified a great amount of variation in the aims, methodologies and assessment approaches in the interventions available. They argue that there is need for greater specificity about the term "ethics", educators should set clear and well-defined goals for teaching ethics and they should be able to provide evidence to community about the effectiveness of their approaches with respect to the aforementioned goals.

Bates et al. (2020) identified various challenges in integrating ethical and societal dimensions into programmes. For example, forming a curriculum that is based on ethical values can be challenging when teaching has to accommodate students coming in with different cultural values to their academic teachers. Also, an interdisciplinary approach to teaching ethics and critical thinking skills might run into the obstacle of miscommunication due to different fields of expertise that have to work together.

It is worth noting that much of the research on the teaching of computer ethics focuses on US institutions and there is a lack of comprehensive data on the teaching 
of computer ethics in Computer Science from a European perspective. Our study aims to contribute towards shedding more light on what is the situation regarding European Computer Science and related programmes. In the next sections, we outline the results of a survey of 61 universities across Europe designed to understand the extent to which and how computer ethics is taught on Computer Science and related programmes across Europe.

\section{Methodology}

We designed an online survey to better understand existing practices in the teaching of computer ethics in Computer Science programmes at European Universities. The survey was created using Lime Survey software and was developed in the English language only. The questionnaire was sent to all members and networking partners of Informatics Europe and European Digital Learning Network who are partners in the Ethics4EU project with a reach of reaching 152 European Universities from 30 European countries. It was also publicly available from the Informatics Europe website and shared on a range of social media platforms, including: Twitter, Facebook and relevant LinkedIn groups. The questionnaire was deployed in January 2020 and was available online for 6 weeks. Over the six weeks, weekly reminders asking people to fill out the online questionnaire were sent. In total we received responses from 61 universities from 23 European countries representing a $40 \%$ response rate. Each response is unique for the respective university. Participants did not receive any incentives or remuneration to complete the survey.

The questionnaire (see Appendix) was divided into three sections. Section A surveyed demographic information including the country of the respondent's institution, their role, and the number of students studying Computer Science and related programmes at the institution. The rest of the questionnaire was split into two parts, $\mathrm{B}$ and $\mathrm{C}$, based on whether the institution taught computer ethics as part of any Computer Science or related programmes. Section B was completed by those at institutions that do not teach computer ethics, and amounted to 22 out of 61 responses. The questions in Section B examined the reasons why Computer Science is not taught at those institutions. Section $\mathrm{C}$ was completed by respondents at institutions where computer ethics is taught on their Computer Science and/or related programmes. This amounted to 39 institutions and the questions surveyed how computer ethics is taught, the background of staff who teach computer ethics and the scope of computer ethics curricula.

For reasons beyond the researcher's control there was a larger number of responses from Italian institutions relative to other countries represented in the survey. However, as responses were grouped by whether an institution teaches computer ethics or not, the responses from Italian universities were balanced with the rest of the countries for Section $C$ (institutions that do teach computer ethics). On the other hand, in section B (institutions that do not teach computer ethics), Italian institutions accounted for almost one third of the responses (7 out of 22). Steps were taken to balance the data using Jackknife resampling (Tukey, 1958) whereby each response is systematically left out of the overall sample to ensure that no single 
response has a significant impact on the overall outcome. Additionally, pairs and trios of the responses from the Italian institutions were left out to explore whether or not those responses had a significant impact on the overall trends, and it was found that they did not.

\section{Results}

In this section we present the results of the survey starting with participants' demographic information. The survey reached around 150 academic institutions and 61 of them completed it. This shows a response rate of $41 \%$.

\section{Section A-participant demographics}

\section{What country is your institution primarily based in? (choose only one answer)}

Twenty-three countries were represented in the 61 responses. It is worth noting that the majority of EU member countries are represented here, as well as several other European countries. Respondents from Italy are in the majority, and as discussed responses were analysed and no significant impact of this overrepresentation was found (Fig. 1).

\section{Does your institution teach all subjects or focus on technical ones? (choose only one answer)}

As show in in Table 1, almost one third (31\%) of academic institutions focus on technical subjects, whereas the remaining institutions $(69 \%)$ are general universities that teach a broader range of subjects.

\section{What is your role within your institution? (choose all that apply)}

The majority of the respondents identified as Professor (62\%). 14.75\% identified as Lecturers. Please note that in European counties, lecturers and professors are both full time academic staff who carry out teaching and research duties. Therefore $77 \%$ (Table 2) of respondents have direct teaching experience at an academic institution. It is also helpful that other respondents identify themselves as having academic management roles, given that they would be more acutely aware of challenges associated to resource allocation, which has been identified as a key challenge to the teaching of computer ethics in Computer Science programmes (Grosz et al., 2019; Johnson, 2010; Pease \& Baker, 2009).

Respondents could also provide other roles additionally to those shown in Table 2. The following roles were also provided:

- Vice dean of the faculty

- Associate Professor 


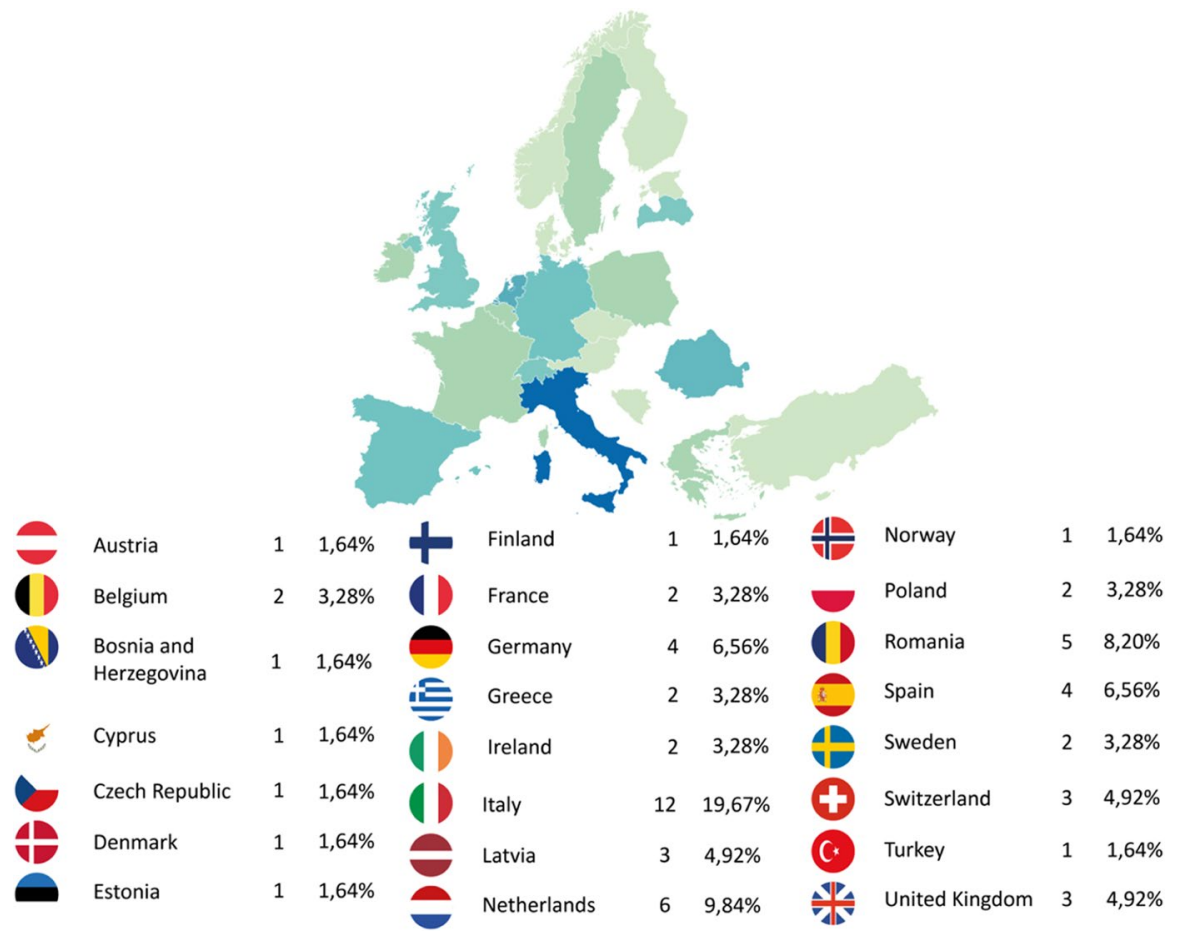

Fig. 1 Countries of participants

Table 1 Type of Institution

\begin{tabular}{lll}
\hline Academic Institution type & Count & $\%$ \\
\hline Teach all subjects & 42 & $69 \%$ \\
Focus on technical ones & 19 & $31 \%$ \\
\hline
\end{tabular}

Table 2 Roles of respondents

\begin{tabular}{lll}
\hline & Count & $\%$ \\
\hline Lecturer & 9 & $15 \%$ \\
Professor & 38 & $62 \%$ \\
Course-Leader & 8 & $13 \%$ \\
Head-of-Department & 12 & $20 \%$ \\
Head-of-School & 4 & $7 \%$ \\
Other & 8 & $13 \%$ \\
\hline
\end{tabular}

- Vice rector and former Head of School

- Head of ethics committee; Research integrity officer

- Teaching and Research Assistant

- Teaching Fellow 
Table 3 Number of students at the surveyed academic institutions

Table 4 Number of students studying on Computer Science or related programmes

\begin{tabular}{lll}
\hline Number of Students & Count & $\%$ \\
\hline $1-1000$ & 4 & $7 \%$ \\
$1001-5000$ & 6 & $10 \%$ \\
$5001-10,000$ & 3 & $5 \%$ \\
$10,001-25,000$ & 22 & $36 \%$ \\
$25,001-50,000$ & 23 & $38 \%$ \\
$50,000+$ & 3 & $5 \%$ \\
\hline
\end{tabular}

\begin{tabular}{lll}
\hline Number of Computing students & Count & $\%$ \\
\hline $1-100$ & 1 & $2 \%$ \\
$101-500$ & 12 & $20 \%$ \\
$501-1001$ & 14 & $23 \%$ \\
$1001-2500$ & 18 & $30 \%$ \\
$2501-5000$ & 10 & $16 \%$ \\
$5000+$ & 6 & $10 \%$
\end{tabular}

- Vice-Dean

- Assistant Professor

Approximately how many students attend your institution? (choose only one answer)

A wide range of academic institutions sizes were represented in the survey (Table 3). The majority of institutions (74\%) had between 10,000 and 50,000 students.

Approximately how many students are studying on Computer Science and/ or Computer Science related programmes (e.g. Informatics, Information Systems, Analytics, Computing for Business, Computer Engineering, etc.)? (choose only one answer)

All academic institutions reported students studying on Computer Science or related programmes. 30\% of institutions surveyed report having between 1001 and 2500 students (Table 4) enrolled in Computer Science and related programmes.

NOTE: A "programme" refers to a complete collection of subjects a student had to study before achieving a qualification, e.g. a BSc in Computer Science. 
Table 5 Degrees offered by each institution

\begin{tabular}{lll}
\hline Degree levels offered & Count & $\%$ \\
\hline Bachelor \& Master \& PhD & 55 & $90 \%$ \\
Bachelor only & 1 & $2 \%$ \\
Bachelor and Master only & 2 & $3 \%$ \\
Master and PhD only & 1 & $2 \%$ \\
PhD only & 2 & $3 \%$ \\
\hline
\end{tabular}

Table 6 How important is it to teach ethics on Computer Science (and related) programmes

\begin{tabular}{lll}
\hline & Count & $\%$ \\
\hline 1= Not at all important & 0 & $0 \%$ \\
2- Somewhat important & 3 & $14 \%$ \\
3- Neither important or unimportant & 5 & $23 \%$ \\
4= Important & 8 & $36 \%$ \\
5=Very Important & 6 & $27 \%$ \\
\hline
\end{tabular}

\section{At what level does your institution teach Computer Science and/or Computer Science related programmes? (choose all that apply)}

Of the 61 academic institutions surveyed, only 3 exclusively teach postgraduate programmes, and 1 exclusively teaches undergraduate programmes, with majority (90) teaching a combination of both (Table 5).

\section{Section B-Institutions that do not teach ethics as part of their Computer Science and/or Computer Science related programmes}

A total of 22 responses from 61 countries were received from academic institutions that do not teach computer ethics on their Computer Science (and related) programmes. Of those responses, 21 came from institutions that teach all academic subject areas and only 1 from an institution that focuses on technical subjects. In our dataset, almost one third (7 out of 22) of those responses were from Italian institutions. In response to this overrepresentation, Jackknife resampling was applied to estimate the bias of the sample and no significant impact was found. The rest of the institutions were spread geographically across Europe.

How important do you think it is that ethics is taught on Computer Science and/ or Computer Science related programmes?

In academic institutions that do not teach computer ethics, almost two-thirds (63\%) of the respondents' consider the teaching of computer ethics as either being "Important" or "Very Important" for Computer Science (and related) programmes (Table 6). 


\section{Please explain in a sentence or two why you answered the previous question the way you did}

The respondents gave a range of reasons as to why the teaching of computer ethics is important. The.

most common was the ever-growing impact that computers have on society which was mentioned by almost $50 \%$ of the respondents. Some of the respondents highlighted specific areas within Computer Science where they believe computer ethics is important-Data Science, Artificial Intelligence, Computer Security and Ubiquitous Computing were mentioned multiple times.

In terms of content delivery, some respondents felt that computer ethics should be taught by incorporating it into existing modules, whereas others felt it should be delivered as an optional module. Specific content that respondents suggested included Codes of Ethics, Intellectual Property rights, privacy, as well as the broader areas of software design and development and where computer ethics fits into those processes.

Those who felt that there was not a need to teach computer ethics suggested it was because employers don't ask for it, it's not the most important thing to teach on a Computer Science (or related) programme, and that teaching it is not cost effective. Others claimed that teaching computer ethics would not help students become more ethical as they should already know about ethics before they come to university - from previous schooling and their family. One respondent claimed that ethics isn't taught in other non-natural science programmes, so wondered why Computer Science should be different; and another suggested it is only relevant in Computer Science research, not teaching.

\section{Rate the following as reasons why ethics is not taught on your Computer Science and/or Computer Science related programmes}

Respondents were asked to select from a number of possible options outlining why computer ethics is not taught (see Table 7). The main reasons the academic institutions do not teach it is a lack of time (73\%) and a lack of staff availability (73\%). Half of the respondents suggests a lack of staff expertise was also a factor. The responses reaffirm the notion that the majority of respondents do believe that

Table 7 Reasons why ethics is not taught

\begin{tabular}{llll}
\hline & $\begin{array}{l}\text { Somewhat disagree up } \\
\text { to fully disagree }\end{array}$ & $\begin{array}{l}\text { Neither agree nor } \\
\text { disagree }\end{array}$ & $\begin{array}{l}\text { Fully agree up to } \\
\text { somewhat agree }\end{array}$ \\
\hline Ethics isn't that important & $71 \%$ & $14 \%$ & $14 \%$ \\
Lack of staff expertise & $18 \%$ & $32 \%$ & $50 \%$ \\
Lack of staff availability & $14 \%$ & $14 \%$ & $73 \%$ \\
Lack of time & $9 \%$ & $18 \%$ & $73 \%$ \\
The content too far away from ethics & $43 \%$ & $48 \%$ & $10 \%$ \\
\hline
\end{tabular}


teaching computer ethics is important event though it is not taught on Computer Science (or related) programmes at their institutions (71\%).

\section{Are there plans to teach ethics on your Computer Science and/or Computer Science related programmes?}

The responses were evenly split between academic institutions that planning to begin teaching computer ethics on their Computer Science (and related) programmes and those who aren't (41\% each). $18 \%$ of respondents did not know (Table 8 ). Respondents were asked to comment on their answer to this question. For those respondents whose institutions are planning to teach computer ethics, the main subject areas mentioned were Data Science, Artificial Intelligence, Computer Security, Health Informatics \& Bioinformatics, Requirements Engineering, and CSCW (ComputerSupported Cooperative Work). One respondent mentioned that their institute are launching an Ethical-Legal stream on their MSc in Data Science programme. For those from institutions with no plans to teach computer ethics, they stated it was due to either a lack of interest or a lack of expertise in the topic. One respondent did mention that students at their institution have the option of doing an ethics module in another faculty as part of their programmes.

\section{Section C-Institutions that do teach ethics as part of their Computer Science and/or Computer Science related programmes}

A total of 39 responses were collected from academic institutions that teach computer ethics in their Computer Science (and related) programmes from 17 countries. Of those responses, 18 came from institutions that only focus on technical subjects and 21 came from institutions that teach all academic subjects areas.

\section{How important do you think it is that ethics is taught on Computer Science and/ or Computer Science related programmes?}

From the institutions that are teaching computer ethics in Computer Science (and related) programmes, $95 \%$ of the respondents rate the teaching of computer ethics as either being "Important" or "Very Important" (Table 9).

\begin{tabular}{lll}
\hline & Count & $\%$ \\
\hline Yes & 9 & $41 \%$ \\
No & 9 & $41 \%$ \\
Don't know & 4 & $18 \%$ \\
\hline
\end{tabular}


Table 9 Importance of teaching ethics on Computer Science (or related) programmes

\begin{tabular}{lll}
\hline & Count & $\%$ \\
\hline 1= Not at all important & 0 & $0 \%$ \\
2- Somewhat important & 1 & $2 \%$ \\
3- Neither important or unimportant & 1 & $3 \%$ \\
4= Important & 8 & $21 \%$ \\
5= Very Important & 28 & $74 \%$ \\
\hline
\end{tabular}

Do you think your institution/department is teaching enough ethics on your Computer Science and/or Computer Science related programmes? (choose only one answer)

Over one-third $(36 \%)$ of the participants responded that do not believe that their intuitions are teaching enough computer ethics in their Computer Science or related programmes (Table 10). Almost half felt enough computer ethics is being taught "to a certain extent".

\section{At what level is ethics taught as part of your Computer Science and/or Computer Science related programmes? (choose all that apply)}

Computer ethics is taught in $26 \%$ of the surveyed institutions at BSc level only (Table 11). In 23\% of the surveyed institutions it is taught at both BSc and MSc level. In 28\% of institutions it is taught at BSc, MSc, and PhD level. The final 23\% represents other combinations, such as "BSc and PhD level" or "MSc level only".

Table 10 Is your institution teaching enough ethics?

\begin{tabular}{lll}
\hline & Count & $\%$ \\
\hline Yes & 6 & $15 \%$ \\
To a certain extent & 19 & $49 \%$ \\
No & 14 & $36 \%$ \\
\hline
\end{tabular}

Table 11 Level at which ethics is taught

\begin{tabular}{lll}
\hline & count & $\%$ \\
\hline BSc only & 10 & $26 \%$ \\
BSc \& MSc & 9 & $23 \%$ \\
BSc \& MSc \& PhD & 11 & $28 \%$ \\
Other combinations & 9 & $23 \%$ \\
\hline
\end{tabular}


Table 12 How ethics is taught

\begin{tabular}{lll}
\hline & Count & $\%$ \\
\hline Threaded throughout several modules & 11 & $28 \%$ \\
As a stand-alone module & 15 & $38 \%$ \\
A combination of both above approaches & 13 & $33 \%$ \\
\hline
\end{tabular}

Table 13 Background of staff who teach ethics

\begin{tabular}{lll}
\hline & Count & $\%$ \\
\hline Computer Science & 28 & $72 \%$ \\
Ethics & 17 & $44 \%$ \\
Philosophy & 12 & $31 \%$ \\
Sociology & 6 & $15 \%$ \\
Legal studies & 9 & $23 \%$ \\
Other & 4 & $10 \%$ \\
\hline
\end{tabular}

How is ethics taught on your Computer Science and/or Computer Science related programmes? (choose only one answer)

NOTE: in this case, a "module" refers to a single topic that a student studies over one or two semesters, e.g. Databases, Computer Networks, etc.

This question explores if computer ethics is being taught as a stand-alone module, or distributed throughout several modules, or a combination of both (Table 12). In the majority of institutions (38\%), computer ethics is taught as a standalone module.

\section{Which background does the person or people who teach ethics in your Computer Science and/or Computer Science related programmes have? (choose all that apply)}

The results presented in Table 13 show that staff teaching computer ethics at the surveyed institutions come from a wide variety of backgrounds, with many coming from multiple disciplines. The most represented discipline is Computer Science at $72 \%$. However, a large number of those teaching computer ethics have backgrounds in Ethics, Philosophy and Law. Please note that respondents could choose more than one background and as such the percentage sum is higher than $100 \%$.

Other backgrounds were provided by respondents in free text answers and included: "Economics"; "Linguistics, Cognitive Science".

\section{Which of the following teaching methods are used to teach ethics on your Computer Science and/or Computer Science related programmes?}

Traditional approaches to teaching, such as "Lecturing" and "Case Studies" are the popular approaches to teaching computer ethics, with "Debates" and "Problem Based Learning" the next most popular pair of approaches (see Table 14). Guest 
Table 14 How is ethics taught?

\begin{tabular}{|c|c|c|c|}
\hline & Seldom to never & Sometimes & $\begin{array}{l}\text { Occasion- } \\
\text { ally to } \\
\text { regularly }\end{array}$ \\
\hline Lectures & $5 \%$ & $14 \%$ & $81 \%$ \\
\hline Case Studies & $14 \%$ & $17 \%$ & $69 \%$ \\
\hline Debates & $24 \%$ & $24 \%$ & $52 \%$ \\
\hline Project-Based/Problem-Based Learning & $41 \%$ & $18 \%$ & $41 \%$ \\
\hline Guest Lecturers (academic) & $40 \%$ & $29 \%$ & $31 \%$ \\
\hline Guest Lecturers (industry) & $74 \%$ & $6 \%$ & $21 \%$ \\
\hline Role-playing & $78 \%$ & $9 \%$ & $13 \%$ \\
\hline eLearning Blended Learning & $75 \%$ & $13 \%$ & $13 \%$ \\
\hline Work-Based Learning & $72 \%$ & $16 \%$ & $13 \%$ \\
\hline Guest Lecturers (government-bodies) & $84 \%$ & $9 \%$ & $6 \%$ \\
\hline Guest Lecturers (professional bodies) & $82 \%$ & $12 \%$ & $6 \%$ \\
\hline
\end{tabular}

Lectures are also relatively popular. Other methods listed in respondents comments includes:

- Groupwork, Peer Instruction (using PeerWise), Student Discussions

- Seminars and Guest lecturers from the Arts

- Interviews with Researchers

- Student Presentations

- Embedded Videos

How many teaching hours per semester is devoted to ethics on your Computer Science and/or Computer Science related programmes? (choose only one answer)

Table 15 Teaching hours devoted to ethics

\begin{tabular}{lll}
\hline & Count & Percent \\
\hline $0-1 \mathrm{~h}$ & 6 & $15 \%$ \\
$2-5 \mathrm{~h}$ & 13 & $33 \%$ \\
$6-10 \mathrm{~h}$ & 7 & $18 \%$ \\
$11-20 \mathrm{~h}$ & 4 & $10 \%$ \\
$20+$ hours & 7 & $18 \%$ \\
Don't know & 2 & $5 \%$ \\
\hline
\end{tabular}

Just under half of all respondents (48\%) indicated that they teach between up to $5 \mathrm{~h}$ per semester, in contrast to $18 \%$ of respondents who indicated that they teach 
Table 16 Ethical topics

\begin{tabular}{llll}
\hline & Infrequently to Never & Sometimes & $\begin{array}{l}\text { Occasionally } \\
\text { to Regularly }\end{array}$ \\
\hline $\begin{array}{l}\text { Ethical Issues } \\
\text { Code of Ethics Professional-bodies IEEE/ }\end{array}$ & $8 \%$ & $16 \%$ & $76 \%$ \\
$\quad$ ACM & $23 \%$ & $26 \%$ & $51 \%$ \\
Ethics Theory & $38 \%$ & $12 \%$ & $50 \%$ \\
Argumentation & $38 \%$ & $25 \%$ & $38 \%$ \\
Code of Ethics National bodies & $55 \%$ & $26 \%$ & $19 \%$ \\
Code of Ethics IT companies & $61 \%$ & $23 \%$ & $16 \%$ \\
\hline
\end{tabular}

computer ethics for $20+$ hours per semester (Table 15). There is clearly a large difference to the amount of time the surveyed institutions devote to the teaching of computer ethics in Computer Science (and related) programmes Table 16.

\section{Which ethical topics are taught on your Computer Science and/or Computer Science related programmes?}

The most common topic is ethical issues with respondents commenting that these are topics specific to subjects (e.g. Data Science). Just over half of the respondents $(51 \%)$ said that Code of Ethics from a professional body are taught at their institutions and exactly half (50\%) teach Ethical Theory. Other topics mentioned in respondents comments included:

- Responsibility

- Legal Issues

- Ethics Washing

- Epistemic Issues

- EU Ethics

\section{How is ethics assessed on your Computer Science and/or Computer Science related programmes? (choose all that apply)}

The top three methods of assessing students' understanding of computer ethics are Exams, Essays, and Presentations; three quite standard approaches to assessing Computer Science content. With much lower representation we find Quizzes, Portfolios, and Rubrics (Table 17). Some other approaches mentioned by respondents included methods such as Debates, Peer Instruction, and Discussion, and dynamic and real-world approaches such as Risk Analysis, Real Use Cases, and Videos. 
Table 17 How ethics is assessed

\begin{tabular}{lll}
\hline & Count & $\%$ \\
\hline Exams & 26 & $68 \%$ \\
Essays & 25 & $64 \%$ \\
Quizzes & 11 & $28 \%$ \\
Rubrics & 3 & $8 \%$ \\
Presentations & 21 & $54 \%$ \\
Portfolios & 4 & $10 \%$ \\
\hline
\end{tabular}

\section{Does your institution teach ethics as part of any of the computing topics outlined below? (These classifications are based on criteria by ACM - Association for Computing Machinery)}

The survey used the European Research Council's Peer Evaluation (PE) panel classifications of Computer Science (PE6) disciplines. The categories are as follows:

- PE6_1: Computer architecture, pervasive computing, ubiquitous computing

- PE6_2: Computer systems, parallel/distributed systems, sensor networks, embedded systems, cyber-physical systems

- PE6_3: Software engineering, operating systems, computer languages

- PE6_4: Theoretical computer science, formal methods, and quantum computing

- PE6_5: Cryptology, security, privacy, quantum crypto

- PE6_6: Algorithms, distributed, parallel and network algorithms, algorithmic game theory

- PE6_7: Artificial intelligence, intelligent systems, multi agent systems

- PE6_8: Computer graphics, computer vision, multi-media, computer games

- PE6_9: Human computer interaction and interface, visualization and natural language processing

- PE6_10: Web and information systems, database systems, information retrieval and digital libraries, data fusion

- PE6_11: Machine learning, statistical data processing and applications using signal processing (e.g. speech, image, video)

- PE6_12: Scientific computing, simulation and modelling tools

- PE6_13: Bioinformatics, biocomputing, and DNA and molecular computation

Respondents to indicate "Yes" or "No" as to whether or not they taught ethical content for each topic. The results are presented in Fig. 2.

The PE6 areas considered to be most important in terms of teaching computer ethics were:

1. PE6_7 Artificial Intelligence, Intelligent Systems, Multi Agent Systems

2. PE6_5 Cryptology, Security, Privacy, Quantum Crypto

3. PE6_9 Human Computer Interaction and Interface, Visualization and Natural Language Processing 


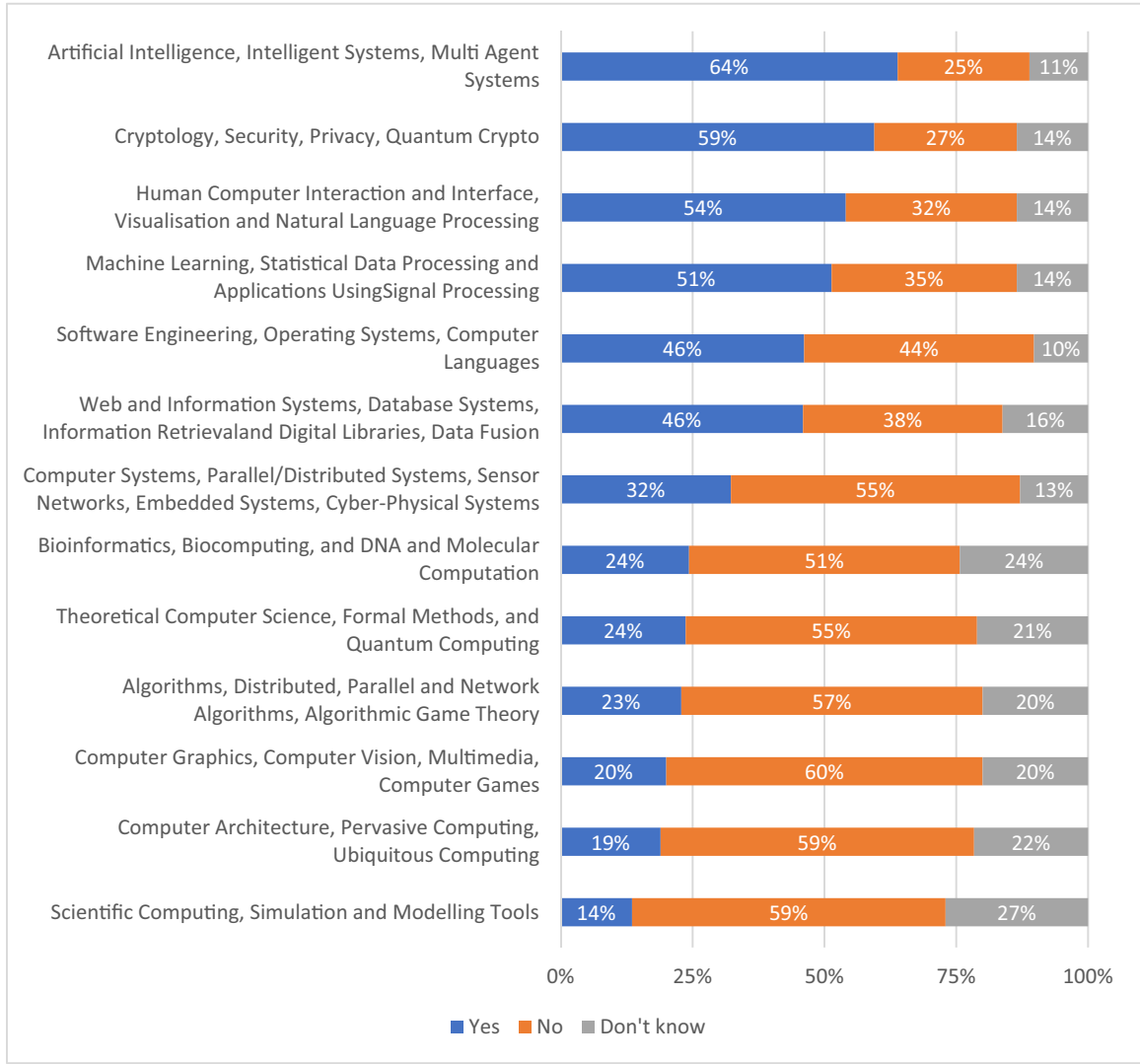

Fig. 2 Computing topics where ethics is taught

The PE6 areas considered to be least important in terms of teaching:

1. PE6_8 Computer graphics, computer vision, multi-media, computer games

2. PE6_1 Computer architecture, pervasive computing, ubiquitous computing

3. PE6_12 Scientific Computing, Simulation and Modelling Tools

It is perhaps not surprising that Artificial Intelligence, Security and Privacy ranked highly in topics that are taught as these are mentioned frequently by respondents as areas where there are important computer ethics issues to be considered, for example as indicated by responses outlined in Sect. 4.3.3 and Sect. 4.3.8. It is surprising however that pervasive and ubiquitous computing and simulation and modelling ranked so lowly on the list of topics taught given the important ethical dimensions to these topics. 


\section{Discussion}

We have presented the results of a survey that polled faculty from Computer Science and related disciplines on teaching practices in computer ethics in Computer Science and related programmes across Europe. The survey was completed by respondents from 61 universities across 23 European countries. Some of the interesting findings that emerged from the survey include:

- Two thirds of the institutions surveyed teach computer ethics as part of Computer Science (or related) programmes, however one third do not.

- There is widespread agreement about the importance of teaching computer ethics to students enrolled on Computer Science (or related) programmes. This importance was noted whether or not an institute taught computer ethics as part of their Computer Science or related programmes.

- Computer ethics is often taught as a standalone subject.

- When computer ethics is not taught as part of Computer Science (or related) programmes the most common reasons cited are a lack of staff availability and expertise.

- Computer ethics is considered more important for certain Computer Science topics. For example Data Science, Artificial Intelligence and Computer Security.

- Most institutions devote a relatively small number of hours to teaching computer ethics on their Computer Science or related programmes, $67 \%$ of institutions surveyed teach $10 \mathrm{~h}$ or less per semester.

As noted from the survey computer ethics is considered more important by many respondents, for certain Computer Science topics. For example, respondents mention the importance of computer ethics with regard to topics such as Data Science, Artificial Intelligence and Computer Security and respondents replied that computer ethics is most commonly taught as part of Artificial Intelligence, Computer Security and Human Computer Interaction courses. There is a great deal of public interest in and media coverage of topics concerning data and Artificial Intelligence applications; they are also topics that are currently undergoing intense academic research. It may be that those who teach computer ethics can more easily locate and identify case studies and other relevant information such as research papers for these topics. For example (Morley et al., 2020), new AI ethics tools are emerging that allow developers to analyse AI and machine learning systems for levels of potential bias. Furthermore, much has been written on the European Union's General Data Protection Regulation which effectively create a "right to explanation," whereby a user can ask for an explanation of an algorithmic decision that was made about them (Goodman \& Flaxman, 2017). This has led to an increase in the literature about how create explainable AI systems (Ras et al., 2018). However, it should not be overlooked that computer ethics is relevant across a range of Computer Science topics including all of the PE6 areas outlined in Fig. 2. Evidently there is a need to develop teaching content and case studies for ethical issues across a broader range of Computer Science topics. 
Our survey also found that computer ethics is often taught as a standalone subject at the academic institutions surveyed. This is in spite of evidence that infusing computer ethics in Computer Science curricula gives students a better understanding of the ethical impacts and possible harmful effects of the technologies they implement (Grosz et al. 2019). According to Grosz, such a "distributed pedagogy" approach reinforces the message that ethical reasoning is part of what you do as a Computer Scientist. Embedding computer ethics across the curriculum helps Computer Science students see how ethical issues can arise from many contexts. Given the increasing likelihood that many Computer Science graduates will work on sociotechnical systems with a variety of impacts on their end users, it is important that Computer Science teaching emphasizes not only the technical capabilities of these systems but also provides students with the ethical reasoning skills to analyse the understand the ethical implications of these systems.

It is also worth noting that our survey found that people who teach computer ethics to Computer Science students are more likely to come from a technical background rather than an Ethics background. The question of who should teach computer ethics to Computer Science students raises questions about the goals of teaching computer ethics. If the goal is to raise awareness of the ethical issues surrounding computers and to develop analytical skills for ethical decision making then it would seem that it is more appropriate for Ethicists to teach this content (D. Johnson, 1994). However, many ethical topics in Computer Science require a deep understanding of the technology that gives rise to the ethical questions, for example the complex mathematical structures that underpin deep learning algorithms. To increase both the breadth and depth of computer ethics teaching, content would be best developed via collaborations between Computer Scientists and Ethicists.

It is also noteworthy that looking at the responses from Sect. 4.3.6, when teaching computer ethics, guest lecturers from industry and professional bodies are not widely used. Taking this in conjunction with the responses from Sect. 4.3 .8 which indicates that the least frequent type of teaching is through the use of different corporations' codes of ethics, followed by national bodies' codes of ethics (although teaching using professionally bodies' codes of ethics is far more common), this may suggest that the connection between computer ethics and the relevant sectorial industry needs to be further emphasised. This is important, as one of the key aims of this research is to produce teaching content that will equip students with a working knowledge of the types of ethically quandaries that they may encounter in their working lives. Therefore, having guest lecturers from industry, and particularly from local or national industry, that may be more readily identifiable with by the students, may help underscore the relevance of computer ethics to their own future professional careers.

In future work, the Ethics4EU project is that is focused on developing new open computer ethics curricula and learning materials for faculty who teach Computer Science. The design and development of these curricula will be done in collaboration between academics from Computer Science and Ethics. The curricula will consist of teaching content including case studies, in-class activities, assignments and recommended readings. The Ethics4EU project will also establish a community of practice for those who teach computer ethics to share lessons learned. The 
overarching aims of the curricula will be to integrate the teaching of computational methods with ethical reasoning skills and provide students with experience in identifying, confronting, and working through ethical questions across many topics in Computer Science. Such skills will equip graduates to produce socially responsible computer technology with benefits for all of society.

\section{Conflicts of interest/Competing interests}

The authors have no conflicts of interest to declare that are relevant to the content of this article.

\section{Ethics}

This research was undertaken using the BERA guidelines as a reference point to ensure that all activities were designed in such a way as to adhere to normal ethical research practices.

\section{Appendix The questionnaire used in the survey}

\section{About Your Institution}

In this survey

- INSTITUTION refers to a University, University College, Technical University, Institute of Technology, Polytechnic University and other types of higher education institutions;

- PROGRAMME refers to a complete collection of subjects a student had to study before achieving a qualification, e.g. a BSc in Computer Science;

- MODULE refers to a single topic that a student studies over one or two semesters, e.g. Databases, Computer Networks, etc. 
1. What country is your institution primarily based in? (choose only one answer)

\begin{tabular}{l|l}
\cline { 2 - 2 } Albania & \\
\hline Andorra & \\
\hline Armenia & \\
\hline Austria & \\
\hline Azerbaijan & \\
\hline Belarus & \\
\hline Belgium & \\
\hline Bosnia and & \\
Herzegovina & \\
\hline Bulgaria & \\
\hline Croatia & \\
\hline Cyprus & \\
\hline Czech Republic & \\
\hline Denmark & \\
\hline Estonia & \\
\hline Finland & \\
\hline France & \\
\hline Georgia & \\
\hline Germany & \\
\hline Greece & \\
\hline Hungary & \\
\hline Iceland & \\
\hline Ireland & \\
\hline Italy & \\
\hline Kazakhstan & \\
\hline Kosovo & \\
\hline
\end{tabular}

\begin{tabular}{l|l|}
\cline { 2 - 2 } Latvia & \\
\hline Liechtenstein & \\
\hline Lithuania & \\
\hline Luxembourg & \\
\hline Malta & \\
\hline Moldova & \\
\hline Monaco & \\
\hline Montenegro & \\
\hline Netherlands & \\
\hline North Macedonia & \\
\hline Norway & \\
\hline Poland & \\
\hline Portugal & \\
\hline Romania & \\
\hline Russia & \\
\hline San Marino & \\
\hline Serbia & \\
\hline Slovakia & \\
\hline Slovenia & \\
\hline Spain & \\
\hline Sweden & \\
\hline Switzerland & \\
\hline Turkey & \\
\hline Ukraine & \\
\hline United Kingdom & \\
\hline
\end{tabular}

2. Does your institution teach all subjects or focus on technical ones? (choose only one answer)

Teach all subjects

Focus on technical ones 
3. What is your role within your institution? (choose all that apply)
Lecturer
Professor
Course Leader
Head of Department
Head of School
Other:

4. Approximately how many students in total attend your institution? (choose only one answer)
$1-1000$
$1001-5000$
$5001-10000$
$10001-25000$
$25001-50000$
$50000+$

5. Approximately how many students are studying on Computer Science or Computer Science related programmes (e.g. Informatics, Information Systems, Analytics, Computing for Business, Computer Engineering, etc.)? (choose only one answer)

$1-100$

101-500

501-1001

1001-2500

2501-5000

$5000+$ 
6. At what level does your institution teach Computer Science and/or Computer Science related programmes? (choose all that apply)

- Bachelor
- Master
- PhD

\section{Does your institution teach ethics as part of any Computer Science and/or} Computer science related programmes? (choose only one answer)

\footnotetext{
Yes

No
}

PROGRAMME refers to a complete collection of subjects a student had to study before achieving a qualification, e.g. a BSc in Computer Science.

Your institution is not currently teaching ethics as part of your Computer Science and/or Computer Science related programmes

Only answer this section if your answer was 'NO' at question '7. Does your institution teach ethics as part of any computer science and/or computer science related programmes?'

1. How important do you think it is that ethics is taught in a Computer Science and/or Computer Science related programme? (1=not at all important, 5=very important)
1
2
4
5

3

PROGRAMME refers to a complete collection of subjects a student had to study before achieving a qualification, e.g. a BSc in Computer Science. 
2. Please explain in a sentence or two why you answered the previous question the way you did.

Please write your answer here:

3. Rate the following as reasons why ethics is not taught as part of your Computer Science and/or Computer Science related programmes

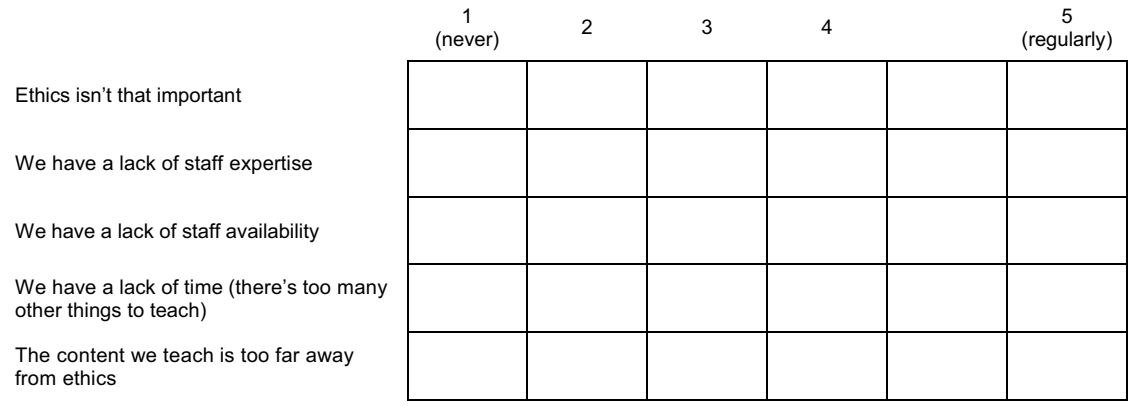

If none of the reasons above fits, specify your reason why ethics isn't taught on Computer Science and/or Computer Science related programmes at your institution.

Please write your answer here:

\section{Are there plans to teach ethics on Computer Science and/or Computer Science related programmes at your institution?}
Yes
No
Don't know

Acknowledgements The European Commission's support for the production of this publication does not constitute an endorsement of the contents, which reflect the views only of the authors, and the Commission cannot be held responsible for any use which may be made of the information contained therein.

Authors contributions All authors were involved in drafting and reviewing the survey instrument, reviewing the content of the paper and contributing to the authorship.

Funding This paper is part of the Ethics4EU project which is Co-funded by the Erasmus + Programme of the European Union under Grant Agreement No 2019-1-IE02-KA203-000665. 
Data Availability All materials and data related to survey is available.

Open Access This article is licensed under a Creative Commons Attribution 4.0 International License, which permits use, sharing, adaptation, distribution and reproduction in any medium or format, as long as you give appropriate credit to the original author(s) and the source, provide a link to the Creative Commons licence, and indicate if changes were made. The images or other third party material in this article are included in the article's Creative Commons licence, unless indicated otherwise in a credit line to the material. If material is not included in the article's Creative Commons licence and your intended use is not permitted by statutory regulation or exceeds the permitted use, you will need to obtain permission directly from the copyright holder. To view a copy of this licence, visit http://creativecommons.org/licen ses/by/4.0/.

\section{References}

Bates, J., Cameron, D., Checco, A., Clough, P., Hopfgartner, F., Mazumdar, S., Sbaffi, L., Stordy, P., and de la Vega de León, A. 2020. Integrating FATE/critical data studies into data science curricula: where are we going and how do we get there? Proceedings of the 2020 Conference on Fairness, Accountability, and Transparency, 425-435. https://doi.org/10.1145/3351095.3372832.

Brodnik, A., and C. Lewin. 2017. Guest editorial for special section on a new culture of learning: Developing computing in the curriculum and advancing digital pedagogy. Education and Information Technologies 22 (2): 417-420. https://doi.org/10.1007/s10639-017-9581-6.

Bynum, T.W. 2000. The foundation of computer ethics. ACM SIGCAS Computers and Society 30 (2): 6-13. https://doi.org/10.1145/572230.572231.

Bynum, T. W. 2008. Milestones in the history of information and computer ethics. In The handbook of information and computer ethics, ed. K. E, Himma, H. T. Tavani, 25-48. John Wiley \& Sons. https://doi.org/10.1002/9780470281819.ch2.

Bynum, T. W. 1992. Computer ethics in the computer science curriculum. In Teaching computer ethics, ed. T. W., Bynum, W., Maner, J. L. Fodor, 12-40. Southern Connecticut State University.

Dexter, S., Buchanan, E., Dins, K., Fleischmann, K. R., and Miller, K. 2013. Characterizing the need for graduate ethics education. SIGCSE 2013 - Proceedings of the 44th ACM Technical Symposium on Computer Science Education, 153-158. https://doi.org/10.1145/2445196.2445245

Dodig-Crnkovic, G. 2003. Shifting the paradigm of philosophy of science: Philosophy of information and a new renaissance. Minds and Machines 13 (4): 521-536.

Ethics4EU. (2021). Existing competencies in the teaching of ethics in computer science faculties. Erasmus+ Project. http://ethics4eu.eu/outcomes/existing-competencies-in-the-teaching-of-ethics-incomputer-science-faculties-research-report/

Ferrarello, Laura. 2019. Conference or workshop, social awareness in design \& engineering education and practice: the value of ethics in postgraduate education at 21st International Conference on Engineering \& Product Design Education, Glasgow, 12th-13th September 2019. https://doi.org/10. 35199/epde2019.83.

Fiesler, C., Garrett, N., and Beard, N. 2020. What do de teach when we teach tech ethics? A syllabi analysis. Proceedings of the 51st ACM Technical Symposium on Computer Science Education (SIGCSE '20), 289-295. https://doi.org/10.1145/3328778.3366825.

Friedman, B., and Hendry, D. G. 2012. The envisioning cards: A toolkit for catalyzing humanistic and technical imaginations. In Proceedings of the SIGCHI Conference on Human Factors in Computing Systems, 1145-1148. Association for computing machinery. https://doi.org/10.1145/2207676.22085 62.

Fuller, U., J.C. Little, B. Keim, C. Riedesel, D. Fitch, and S. White. 2010. Perspectives on developing and assessing professional values in computing. ACM SIGCSE Bulletin 41 (4): 174-194. https://doi.org/ 10.1145/1709424.1709461.

Ghafarian, A. 2002. Integrating ethical issues into the undergraduate computer science curriculum. Journal of Computing Sciences in Colleges 18 (2): 180-188.

Goodman, B., and S. Flaxman. 2017. European Union regulations on algorithmic decision-making and a "right to explanation." AI Magazine 38 (3): 50-57.

Gotterbarn, D. 1991. Computer ethics: Responsibility regained. National. Forum 71 (3): 26. 
Grosz, B.J., D.G. Grant, K. Vredenburgh, J. Behrends, L. Hu, A. Simmons, and J. Waldo. 2019. Embedded EthiCS: Integrating ethics across CS education. Communications of the ACM 62 (8): 54-61. https://doi.org/10.1145/3330794.

Harris, A.L., M. Lang, D. Yates, and S.E. Kruck. 2019. Incorporating ethics and social responsibility in IS education. Journal of Information Systems Education 22 (3): 1.

Hess, J.L., and G. Fore. 2018. A systematic literature review of US engineering ethics interventions. Science and Engineering Ethics 24 (2): 551-583.

Iqbal, J., and B.M. Beigh. 2017. Computer ethics: Job of computer scientist. International Journal of Advanced Research in Computer Science and Software Engineering 7 (6): 41-49. https://doi.org/10. 23956/ijarcsse/v7i6/0135.

Johnson, D. 1985. Computer ethics. Prentice Hall.

Johnson, D. 1994. Who should teach computer ethics and computers \& society? ACM SIGCAS Computers and Society 24 (2): 6-13.

Johnson, J. (2010). Teaching ethics to science students: Challenges and a strategy. In Education and ethics in the life sciences: Strengthening the prohibition of biological weapons, ed. B. Rappert, 197214. http://www.jstor.org/stable/j.ctt24hc5p.17

Kesar, S. 2016. Including teaching ethics into pedagogy: Preparing information systems students to meet global challenges of real business settings. ACM SIGCAS Computers and Society 45 (3): 432-437.

Kortsarts, Y., and A. Fischbach. 2014. Incorporating professional ethics into an introductory computer science course. Journal of Computing Sciences in Colleges 29 (3): 35-42.

Kraft, T. 2011. Computer ethics: A slow fade from black and white to shades of gray. Information Systems Education Journal 9 (4): 37.

Larson, D.K., and K.W. Miller. 2018. Action ethics: Testing and data analysis. ACM Inroads 9 (1): 34-37.

Lester, L.-J.Y., and Y. Dalat-Ward. 2019. Teaching professionalism and ethics in information technology by deliberative dialogue. Information Systems Education Journal 17 (1): 4.

Moor, J.H. 1985. What is computer ethics? Metaphilosophy 16 (4): 266-275.

Morley, J., L. Floridi, L. Kinsey, and A. Elhalal. 2020. From what to how: An initial review of publicly available AI ethics tools, methods and research to translate principles into practices. Science and Engineering Ethics 26 (4): 2141-2168.

Passey, D. 2017. Computer science (CS) in the compulsory education curriculum: Implications for future research. Education and Information Technologies 22 (2): 421-443. https://doi.org/10.1007/ s10639-016-9475-z.

Pease, A., and R. Baker. 2009. Union College's Rapaport Everyday Ethics Across the Curriculum Initiative. Teaching Ethics 9 (2): 5-24.

Quinn, M. J. 2007. Case-based analysis: A practical tool for teaching computer ethics. In Proceedings of the Thirty-Seventh SIGCSE Technical Symposium on Computer Science Education (pp. 520-524). Association for computing machinery. https://doi.org/10.1145/1121341.1121503.

Ras, G., van Gerven, M., and Haselager, P. 2018. Explanation methods in deep learning: Users, values, concerns and challenges. In Explainable and Interpretable Models in Computer Vision and Machine Learning, ed. H. J. Escalante, S. Escalera, I. Guyon, X. Baró, Y. Güçlütürk, U. Güçlü, \& M. van Gerven, 19-36. Springer International Publishing. https://doi.org/10.1007/978-3-319-98131-4_2.

Reich, R., Sahami, M., Weinstein, J. M., \& Cohen, H. (2020). Teaching computer ethics: A deeply multidisciplinary approach. Annual Conference on Innovation and Technology in Computer Science Education, ITiCSE, 296-302. https://doi.org/10.1145/3328778.3366951

Saltz, J., M. Skirpan, C. Fiesler, M. Gorelick, T. Yeh, R. Heckman, N. Dewar, and N. Beard. 2019. Integrating ethics within machine learning courses. ACM Transactions on Computing Education (TOCE) 19 (4): 1-26.

Scott, A., \& Barlowe, S. (2016). How software works: Computational thinking and ethics before CS1. Proceedings - Frontiers in Education Conference, FIE, 2016-Novem. https://doi.org/10.1109/FIE. 2016.7757436

Sentance, S., and A. Csizmadia. 2017. Computing in the curriculum: Challenges and strategies from a teacher's perspective. Education and Information Technologies 22 (2): 469-495. https://doi.org/10. 1007/s10639-016-9482-0.

Shen, H., Deng, W. H., Chattopadhyay, A., Wu, Z. S., Wang, X. and Zhu, H. 2021. Value cards: An educational toolkit for teaching social impacts of machine learning through deliberation. Proceedings of the 2021 ACM Conference on Fairness, Accountability, and Transparency, 850-861. https://doi.org/ $10.1145 / 3442188.3445971$. 
Skirpan, M., Beard, N., Bhaduri, S., Fiesler, C., \& Yeh, T. (2018). Ethics education in context: A case study of novel ethics activities for the CS classroom. SIGCSE 2018 - Proceedings of the 49th ACM Technical Symposium on Computer Science Education, 2018-Janua, 940-945. https://doi.org/10. $1145 / 3159450.3159573$

Stahl, B.C., J. Timmermans, and B.D. Mittelstadt. 2016. The ethics of computing: A survey of the computing-oriented literature. Acm Computing Surveys (CSUR) 48 (4): 1-38.

Tucker, A.B. 1991. Computing curricula 1991. Communications of the ACM 34 (6): 68-84.

Tukey, J. W. 1958. Bias and confidence in not quite large samples. Annals of Mathematical Statistics 29: 614. http://ci.nii.ac.jp/naid/10026575637/en/.

Weikle, D.A.B. 2018. Teaching the code and ethics in computing. ACM SIGCAS Computers and Society 48 (1): 9-11. https://doi.org/10.1145/3264704.3264705.

Wiener, N. 1950. The human use of human beings: Cybernetics and society. Boston: Houghton Mifflin.

Wilk, A. 2019. Teaching AI, ethics, law and policy. ArXiv Preprint ArXiv:1904.12470.

Publisher's Note Springer Nature remains neutral with regard to jurisdictional claims in published maps and institutional affiliations.

\section{Authors and Affiliations}

\section{loannis Stavrakakis ${ }^{1}$ (D) Damian Gordon ${ }^{1} \cdot$ Brendan Tierney $^{1}$.}

Anna Becevel ${ }^{1} \cdot$ Emma Murphy $^{1} \cdot$ Gordana Dodig-Crnkovic $^{2} \cdot$ Radu Dobrin $^{3}$. Viola Schiaffonati ${ }^{4}$. Cristina Pereira ${ }^{5}$. Svetlana Tikhonenko ${ }^{5}$. J. Paul Gibson ${ }^{6}$. Stephane Maag $^{6} \cdot$ Francesco Agresta $^{7} \cdot$ Andrea Curley $^{1} \cdot$ Michael Collins $^{1}$. Dympna O'Sullivan ${ }^{1}$

1 Applied Social Computing Network (ASCNet) Research Group, School of Computer Science, Technological University Dublin, City Campus, Dublin, Ireland

2 Department of Computer Science and Engineering Chalmers University of Technology \& School of Innovation, Design and Engineering, Mälardalen University, Västerås, Sweden

3 School of Innovation, Design and Engineering, Mälardalen University, Västerås, Sweden

4 Department of Electronics, Information and Bioengineering, Politecnico Di Milano, Milan, Italy

5 Informatics Europe, Zurich, Switzerland

6 Télécom SudParis Institut Polytechnique de Paris, Samovar Lab, Paris, France

7 European Digital Learning Network, Milan, Italy 